\title{
Ascending noradrenergic excitation from the locus coeruleus to the anterior cingulate cortex
}

\author{
Kohei Koga ${ }^{1,2,3+}$, Akihiro Yamada ${ }^{3 \dagger}$, Qian Song ${ }^{1,2+}$, Xu-Hui Li ${ }^{1,2}$, Qi-Yu Chen ${ }^{1,2}$, Ren-Hao Liu', Jun Ge ${ }^{4}$, \\ Cheng Zhan ${ }^{5,6}$, Hidemasa Furue ${ }^{3}$, Min Zhuo ${ }^{1,2^{*}}$ and Tao Chen ${ }^{1,4^{*}}$
}

\begin{abstract}
Anterior cingulate cortex (ACC) plays important roles in sensory perception including pain and itch. Neurons in the ACC receive various neuromodulatory inputs from subcortical structures, including locus coeruleus noradrenaline (LC-NA) neurons. Few studies have been reported about synaptic and behavioral functions of LC-NA projections to the ACC. Using viral-genetic method (AAV-DIO-eYFP) on DBH-cre mice, we found that LC-NA formed synaptic connections to ACC pyramidal cells but not interneurons. This is further supported by the electron microscopic study showing NAergic fibers contact the presynaptic inputs and post-synaptic areas of the pyramidal cells. NA application produced both pre- and post-synaptic potentiation effects in ACC excitatory transmission in vivo and in vitro. Activation of LC-NA projection to the ACC by optogenetic method produced enhancement of excitatory transmission in vitro and induced scratching and behavioral sensitization for mechanical stimulation. Our results demonstrate that LC-NA projections enhance or facilitate brain responses to pain and itch by potentiating glutamatergic synaptic transmissions in the ACC.
\end{abstract}

Keywords: Noradrenaline, Anterior cingulate cortex, Glutamatergic transmission, Pyramidal neuron, Layer II/III, Optogenetics

\section{Introduction}

The locus coeruleus (LC) is a main origin of noradrenergic neurons [1-3]. Noradrenaline (NA) is a key neuromodulator to play critical roles in various higher brain functions in the central nervous system (CNS) [1, 2]. In the brain, NA contributes to arousal, attention, cognition and memory $[4,5]$. NA also plays roles as modulatory systems for pain sensation in the spinal dorsal horn [6-8].

Sensory transmission is under the control of endogenous modulatory systems [6,9-12]. Spinal cord plays a

\footnotetext{
* Correspondence: min.zhuo@utoronto.ca; chtkkl@fmmu.edu.cn †Kohei Koga, Akihiro Yamada and Qian Song contributed equally to this work.

${ }^{1}$ Center for Neuron and Disease, Frontier Institute of Science and Technology, Xi'an Jiaotong University, Xi'an 710049, China

Full list of author information is available at the end of the article
}

crucial role in the transmission and modulation of painful information $[13,14]$. It has been reported that spinal noxious sensory transmission can be modulated by descending inhibitory modulation $[6,11]$ and/or facilitatory modulation $[12,15,16]$. The LC is a key structure which contributes to descending modulation of painful information in the spinal cord [17-19]. The activation of LC triggers descending inhibition to the spinal cord, and produces analgesic effect by releasing NA in the spinal cord [6].

In addition to the well-known descending projection, LC sends projections to supraspinal structures including cortical areas $[20,21]$. Cortical areas, including the anterior cingulate cortex (ACC) and the insular cortex (IC), play important roles in chronic pain and emotional responses [20, 22-25]. Selective activations of the ACC and/or IC by electric stimulations or optogenetic 
stimulation induce modulatory effects on nociception and emotion in monkey and rodents study [20, 26, 27]. Electrical stimulation or optogenetic selective activation of pyramidal neurons acutely reduces nociceptive thresholds [26, 27]. In contrast, inhibition of pyramidal neurons in the ACC reduces hypersensitivity induced in chronic inflammatory pain model [26]. A similar analgesic effect was induced by the activation of parvalbumin-expressing interneurons in the ACC [26]. These results in animals are consistent with human imaging studies that demonstrate that the ACC is a critical area for chronic pain [20, 22, 24]. In addition to pain perception, human imaging study show that the ACC is a critical cortical area for itch sensation [28, 29]. Rodent studies demonstrate that itch stimulation can activate neurons in the ACC [30, 31].

Although descending NAergic LC-spinal system has been documented $[4,5]$, the functions of NAergic LCACC projections are not investigated yet. It is unclear if such NAergic projection may also produce analgesic effects as their descending modulation to the spinal dorsal horn. In the present study, we take advance of the optogenetic approach to investigate the selective effect of LCACC projection on synaptic transmissions within the ACC as well as behavioral responses. We found that ascending LC-ACC projections enhance glutamatergic synaptic transmission and neural excitability in the ACC, and facilitated behavioral responses to pain and itch sensory stimulation in mice. Different with the well-known mechanism of NA in the spinal cord level, our work for the first time reveals the mechanism of NA in the LC-cortical ascending pathway in sensory modulation.

\section{Materials and methods}

\section{Animals}

Adult male C57BL/6 and DBH-cre mice (8-12 week old) were used. Male Sprague-Dawley rats (SD rats) were used for in vivo extracellular recording. Adenylyl cyclase type 1 (AC1) knockout (KO) and AC8 $\mathrm{KO}$ mice were a gift from Dr. Daniel R. Storm (University of Washington, Seattle, WA) [32-34] and were maintained on a C57BL/6 background. All mice and rats were maintained on a 12-hlight/ dark cycle (temperature $22-26^{\circ} \mathrm{C}$, air humidity 55-60\%) with food and water provided ad libitum. The Animal Care and Use Committee at the Air Force Medical University and Xian Jiaotong University in China, National Institutes of Natural Sciences in Japan and Hyogo College of Medicine approved the experimental protocols.

\section{In vitro whole-cell patch-clamp recordings in the ACC slices}

Experimental procedures were based on those described previously [35-37]. Briefly, mice were anesthetized with $1-2 \%$ isoflurane and coronal brain slices including the ACC
$(300 \mu \mathrm{m})$ were prepared using standard methods. Slices were transferred to a room temperature-submerged recovery chamber with an oxygenated $\left(95 \% \mathrm{O}_{2}-5 \% \mathrm{CO}_{2}\right)$ artificial cerebrospinal fluid (ACSF) containing (in $\mathrm{mM}$ ) $124 \mathrm{NaCl}, 25$ $\mathrm{NaHCO}_{3}, 2.5 \mathrm{KCl}, 1 \mathrm{KH}_{2} \mathrm{PO}_{4}, 2 \mathrm{CaCl}_{2}, 2 \mathrm{MgSO}_{4}$ and 10 glucose. After a $1 \mathrm{~h}$ recovery period, slices were transferred into a recording chamber on the stage of an Axioskop 2FS microscope (Zeiss) equipped with infrared DIC optics for visualized recordings. All experiments were recorded with an Axon 200B amplifier (Axon Instruments). In the voltageclamp configuration, recording electrodes $(2-5 \mathrm{M} \Omega$ ) contained the pipette solution composed of (in mM) $120 \mathrm{~K}$-gluconate, $5 \mathrm{NaCl}, 1 \mathrm{MgCl}_{2} \quad 0.5$ EGTA, $2 \mathrm{Mg}$-ATP, 0.1 $\mathrm{Na}_{3} \mathrm{GTP}$, and 10 HEPES; pH 7.2, 280-300 mOsm. The membrane potential was held at $-60 \mathrm{mV}$ for recording spontaneous excitatory post-synaptic currents (sEPSCs) and held at $0 \mathrm{mV}$ for recording spontaneous inhibitory postsynaptic currents (sIPSCs). APV $(50 \mu \mathrm{M})$ was always added in the ACSF. Picrotoxin $(100 \mu \mathrm{M})$ was added into the ACSF for recording sEPSCs and CNQX $(25 \mu \mathrm{M})$ was added into the ACSF for recording sIPSCs. The pipette solution was containing (in mM): $\mathrm{Cs}^{-} \mathrm{MeSO}_{3}, 120 ; \mathrm{NaCl}, 5 ; \mathrm{MgCl}_{2} 1$; EGTA, 0.5; Mg-ATP, 2; $\mathrm{Na}_{3} \mathrm{GTP}, 0.1$; HEPES, 10; $\mathrm{pH} 7.2$; 280-300 mOsmol. Pyramidal neurons and interneurons were distinguished based on their morphology, membrane properties and firing pattern (Fig. 6a). The initial access resistance was $15-30 \mathrm{M} \Omega$, and it was monitored throughout the experiment. Data were discarded if the access resistance changed $>15 \%$ during experiment. Data were filtered at 1 $\mathrm{kHz}$, and digitized at $10 \mathrm{kHz}$. Data were collected and analyzed with Clampex and Clampfit 10.2 software (Axon Instruments). NA and NA receptors agonist or antagonists were bath applied in ACSF.

In some cases, biocytin (0.5\%) were added into the pipette solution for labeling the morphology of the recorded pyramidal cells or interneurons. After recording, the slices were fixed in $4 \%$ paraformaldehyde in $0.1 \mathrm{M}$ phosphate buffer (PB, $\mathrm{pH}$ 7.4) for $1 \mathrm{~h}$ at room temperature. Slices were then rinsed with 3\% hydrogen peroxide in PBS for $30 \mathrm{~min}$ and throughly washed with $0.01 \mathrm{M} \mathrm{PBS}$ (pH 7.4). The tissue was then incubated with Alex594 conjugated Streptavidin (1:200, Jackson) for $4 \mathrm{~h}$ at room temperature. The immunofluorescence-labeled sections were then rinsed in PBS, mounted onto glass slides and visualized under confocal microscope under appropriate filter.

\section{In vivo electrophysiology for $\mathrm{ACC}$ recording}

In vivo preparations were made as described previously [38]. Under urethane anesthesia $(1.2-1.5 \mathrm{~g} / \mathrm{kg}$, i.p.), rats were mechanically ventilated after tracheostomy and bilateral thoracotomy was performed. After the head was fixed in a stereotaxic apparatus (Model SR-6R, Narishige, Tokyo, Japan), a craniotomy is performed using a dental drill to open a hole above the ACC according to the stereotaxic 
coordinates. A tungsten electrode (impedance, $10 \mathrm{M} \Omega$, A-M systems, Sequim, WA) was placed into the ACC, and conventional extracellular recordings were obtained as shown previously [39] with an AC differential amplifier (DAM 80, World Precision Instruments, Sarasota, FL). Data were filtered (300 to $5 \mathrm{kHz})$ and digitized $(10 \mathrm{kHz})$. Unit firings were sorted with Offline Sorter software (version 3, Plexon, Dallas, TX). Putative pyramidal neurons in the ACC were identified based on their waveforms as shown previously [40]. In the case of drug microinjection into the ACC, a cannula was inserted through the same hole, and the tip was placed in the vicinity (approximately $1 \mathrm{~mm}$ ) of the recording electrode. Drugs (noradrenaline, $50 \mu \mathrm{g} / 0.5 \mu \mathrm{L}$; phenylephrine, $5 \mu \mathrm{g} / 0.5 \mu \mathrm{L}$; Isoproterenol, $37 \mu \mathrm{g} / 0.5 \mu \mathrm{L}$ ) diluted in normal saline were microinjected over a $5 \mathrm{~min}$ period. For the LC electrical stimulation, a hole was further opened on the skull above the cerebellum ipsilateral to the recording site, and a combined bipolar stimulating electrode-tungsten extracellular recording electrode $(1 \mathrm{M} \Omega$, A-M systems, Sequim, WA) was stereotaxically inserted into the floor of the fourth ventricle above the LC. The electrode was then lowered and placed into the LC if neuronal activity is considered to be obtained from LC neurons. LC neurons were identified based on their characteristic spontaneous firing and responses to contralateral cutaneous noxious stimulation as described previously [41, 42]. Trains of electrical pulses (duration $200 \mu \mathrm{s}$, 50 times, $4 \mathrm{~ms}$ interval) were then applied with an interval of $2 \mathrm{~s}$ for 1-2 min.

\section{Immunohistochemistry}

Immunostaining procedure was applied as described previously [15]. In brief, mice were perfused with $0.1 \mathrm{M}$ PBS and 4\% paraformaldehyde. After fixation, brainstem containing LC and brain containing ACC were removed, cryoprotected and serially cut into transverse slices with $30 \mu \mathrm{m}$ thickness. The sections were then rinsed in PBS with $0.3 \%$ Triton $\mathrm{X}-100$ and $1 \%$ normal goat serum (NGS) for $0.5 \mathrm{~h}$. LC sections were dual-immunostained with GFP and TH. Sections were incubated with mouse anti-GFP antibodies (1:500, Abcam, ab183734) and rabbit anti-TH (1:500, Abcam, ab112) for $24 \mathrm{~h}$, following with Alex594 conjugated anti-rabbit (1:1000, Jackson) and Alexa488 conjugated anti-mouse (1:1000, Jackson) antibodies overnight at room temperature. ACC sections were dual-immunostained for GFP/RFP or GFP/GAD. One set of series sections were incubated with mouse anti-GFP antibodies (1:500, Abcam) and rabbit anti-RFP antibody (1:500, Abcam, ab62341) for $24 \mathrm{~h}$, following with Alex594 conjugated anti-rabbit (1:1000, Jackson) and Alexa488 conjugated anti-mouse (1:1000, Jackson) antibodies overnight at room temperature. Another set of series sections were incubated with mouse anti-GFP antibodies (1:500) and rabbit anti-GAD antibody (1:200, Abcam, ab203063) for $24 \mathrm{~h}$, following with Alex594 conjugated anti-rabbit (1:1000) and Alexa488 conjugated anti-mouse (1:1000) antibodies overnight at room temperature. Sections were then rinsed in PBS, counterstained with DAPI antibodies for 5-10 min and mounted onto glass slides. The signals were visualized under confocal microscope under appropriate filter.

For the electron microscopic staining and observation, mice were deeply anesthetized and then transcardially perfused with normal saline, followed by $0.1 \mathrm{MPB}$ containing $4 \%$ paraformaldehyde, $0.1 \%$ glutaraldehyde and $15 \%$ picric acid. Sections from the brain containing ACC were generated using a vibratome at a $50-\mu \mathrm{m}$ thickness. Sections were then incubated overnight with mouse anti-GFP antibodies (1:200, Abcam) and rabbit anti-RFP antibody (1:200, Abcam), followed by anti-rabbit IgG conjugated to 5-nm gold particles (1:100, Nanoprobes) and biotinylated anti-mouse IgG (1:200, Abcam) for $4 \mathrm{~h}$. Silver enhancement was performed with HQ Silver Kit (Nanoprobes) for visualization of RFP (mCherry) immunoreactivity. Then sections were incubated in the avidin-biotin peroxidase complex for $45 \mathrm{~min}$ and then incubated with diaminobenzidine (DAB) solution. Immunolabelled sections were then fixed with $0.5 \%$ osmium tetroxide in $0.1 \mathrm{M} \mathrm{PB}$ for $1 \mathrm{~h}$, dehydrated in graded ethanol series and then in propylene oxide, and finally flat-embedded in Epon 812 between sheets of plastic. After polymerization, acrylic sheets were peeled from the polymerized resin, and flat-embedded sections were examined under the light microscope. Three to four sections containing GFP and RFP immunoreactivity were selected from each brain, trimmed under a stereomicroscope, and glued onto blank resin stubs. Serial ultrathin sections were cut with an Ultramicrotome using a diamond knife and mounted on formvar-coated mesh grids. They were then counterstained with uranyl acetate and lead citrate, and observed under a JEM-1230 electron microscope.

\section{Behavioural tests}

Four to five weeks after $\mathrm{AAV}_{2 / 9^{-}} \mathrm{hEF1a-DIO-ChR2(H134R)-}$ eYFP or $\mathrm{AAV}_{2 / 9}$-hEFla - DIO-eYFP injection, mice were anesthetized with an intraperitoneal injection of ketaminexylazine $(0.1 \mathrm{mg}$ per gram body weight ketamine, $0.01 \mathrm{mg}$ per gram body weight xylazine) and the head was fixed in a stereotaxic apparatus. A small craniotomy was performed and a hole were drilled. The optic cannula (MFC_200/2300.39_ 2mm_ZF1.25_FLT, Doric Lenses., Quebec, Canada) was implanted in the middle line of ACC $(0.98 \mathrm{~mm}$ anterior to Bregma and $1.0 \mathrm{~mm}$ deep from skull surface). The optic cannula was then fixed with dental cement [15].

One week after optic cannula implantation, mice with ChR2-eYFP or eYFP infection were placed into Lucite cubicles with a plain pedestal to observe the basal behavior. After acclimation for $5 \mathrm{~min}$, optostimulation at 5 or $20 \mathrm{~Hz}(3 \mathrm{~min})$ were applied through the implanted fibers by Master 8 automatically. The whole experiment process was video captured and analyzed by observers. 
The bouts and duration of scratching and wiping behaviors were collected and averaged per min before, during and after optostimulation. For testing the paw withdrawal thresholds, mice were places into Lucite cubicles over a wire mesh with von Frey filaments applied to their left and right hind paws. After acclimation for 5 min, series of filaments $(0.008,0.02,0.04,0.16,0.4,0.6$, $1,1.4,2 \mathrm{~g}$ ) with various bending forces (according to $0.078,0.196,0.392,1.568,3.92,5.88,9.8,13.72,19.6$ $\mathrm{mN}$ ) were manually applied to the plantar surface of the hindpaw until the mice withdrew from the stimulus. The lowest force at which a withdrawal response obtained was considered as the paw withdrawal threshold. The paw withdrawal thresholds before and after optostimulation $(5$ or $20 \mathrm{~Hz}, 3 \mathrm{~min}$ ) were tested. In all experiments, observers were blind to animal grouping.

After behavior test, brains containing ACC were fixed and cut into transverse slices $(30 \mu \mathrm{m})$. The sections were immunostained with rabbit-Fos antibodies (1:300, Abcam, ab190289), following with Alex594 conjugated anti-rabbit (1:1000, Jackson). ACC areas were then observed under confocal microscope for checking the Fos and LC-ACC projecting fiber expression.

\section{Optogenetics}

$\mathrm{AAV}_{2 / 9^{-}}$hEF1a-DIO-ChR2(H134R)-eYFP and $\mathrm{AAV}_{2 / 9^{-}}$ hEF1a-DIO-eYFP were purchased from Taitool Bioscience Co. Ltd. (ShangHai, China) and $\mathrm{AAV}_{2 / 9}$-CaMKII $\alpha-$ mCherry was purchased from BrainVTA Co. Ltd. (WuHan, China). AAV $2 / 9$-DIO-ChR2-eYFP or $\mathrm{AAV}_{2 / 9}$-DIOeYFP $\left(1 \times 10^{13}, 200 \mathrm{~nL}\right.$ per site $)$ were injected into the dual sites of LC and AAV-CaMKII $\alpha$-mCherry $\left(3 \times 10^{12}, 200\right.$ $\mathrm{nL}$ per site) were injected into the dual sites of the ACC in $\mathrm{DBH}$-cre mice. After one month, the immunostaining, whole cell patch recording or in vivo behavioural experiments were carried out, respectively. For performing whole-cell patch recording or in vivo behavioural experiments, optostimulation was applied with 5 or $20 \mathrm{~Hz}$ blue light $(470 \mathrm{~nm}, 5 \mathrm{~ms}$ pulse width in an intensity of $15 \mathrm{~mW} /$ $\mathrm{mm}^{2}$ at the optic fiber tip) $[15,26,43,44]$.

\section{Statistics}

Statistical comparisons were made using the Student $t$ test, one-way or two-way ANOVA as appropriate. Significance between groups was tested with a Holm-Sidak or Tukey tests to adjust for multiple comparisons. All data were presented as the mean \pm S.E.M. In all cases, $P<0.05$ was considered statistically significant.

\section{Results}

\section{Ascending projection from the LC to ACC}

We first used Cre-dependent virus tracing method to examine the NAergic projection from the LC to ACC by injecting AAV-DIO-eYFP into the LC in DBH-cre mice (Fig. 1a).
Most of the NAergic neurons ( $96.4 \pm 2.3 \%$ of TH immunoreactive (ir) neurons, $n=4$ mice) in LC were successively infected (Fig. 1b-c) and their projecting fibers were distributed densely in both sites of the ACC (Fig. 1d). We labelled ACC pyramidal cells by injecting AAV-CaMKII $\alpha$-mCherry into both sites of ACC and found that LC-ACC projection fibers made close connections with mcherry-labeled pyramidal cells (Fig. 1d and e) but did not make close connections with GAD-ir GABAergic neurons (Fig. 1f). To further identify the connection between projecting fibers and pyramidal cells or interneurons, the three-dimensional view was introduced under the confocal microscope. We collected 242 RFPlabeling pyramidal cells (3 mice) and found that 198 (81.8\%) of them were crossed or terminated by NAergic fibers/terminals. From three-dimensional view, it has indicated that the fibers/terminals made close connection with pyramidal cells (yellow dots indicated by arrows in Fig. 1g). However, in 102 GAD-immunostaining GABA neurons, we only found 12 $(11.8 \%)$ of them were crossed by NAergic fibers/terminals. Further three-dimensional view showed that this kind of crossing is not likely to be close connection with, but just passing over the GAD-immunostaining neurons (see the places indicated by arrowheads in Fig. 1g).

Finally, we observed the synaptic connections between LC-ACC projecting fibers and ACC pydamidal cells under the electron microscopy (EM). The NAimmunireactive (ir) products were stained with $\mathrm{DAB}$ and distributed in axon terminals. Pyramidal cells were shown with nano-gold labelled mCherry distributed in the neuronal soma and dendritic spines and shafts. More than half of the identified pyramidal cells' profiles were synapsed by NA-ir terminals $(52.2 \%$ of 232 nano-gold containing profiles), indicating that NA have direct modulatory effect on the pyramidal cells (Fig. $1 \mathrm{~h}$ left panel). NA-ir terminals synapsed with glutamatergic-like axon terminals were frequently observed. In many cases $(n=$ 38), the contacted glutamatergic-like axon terminal also in turn made synapse with a pyramidal cell, suggesting that NA may regulatory the release of glutamate to the pyramidal cell (Fig. 1h right panel).

\section{Effects of NA on excitatory synaptic transmission in the ACC}

Morphological evidence suggest that NA might regulate excitatory glutamatergic inputs, as well as the post-synaptic cellular activities, of pyramidal cells in the ACC. We next performed in vitro whole-cell patch-clamp recording from layer II/III pyramidal cells in the adult mice ACC to examine the modulatory effects of NA. Spontaneous excitatory postsynaptic currents (sEPSCs) were recorded. We found that NA $(10-100 \mu \mathrm{M})$ enhanced the frequency of the sEPSC without affecting the amplitude (Fig. 2a-d). These effects were blocked by application of the $\beta$ receptor antagonist propranolol $(1 \mu \mathrm{M})$. While the $\alpha 1$ receptor antagonist prazosin 


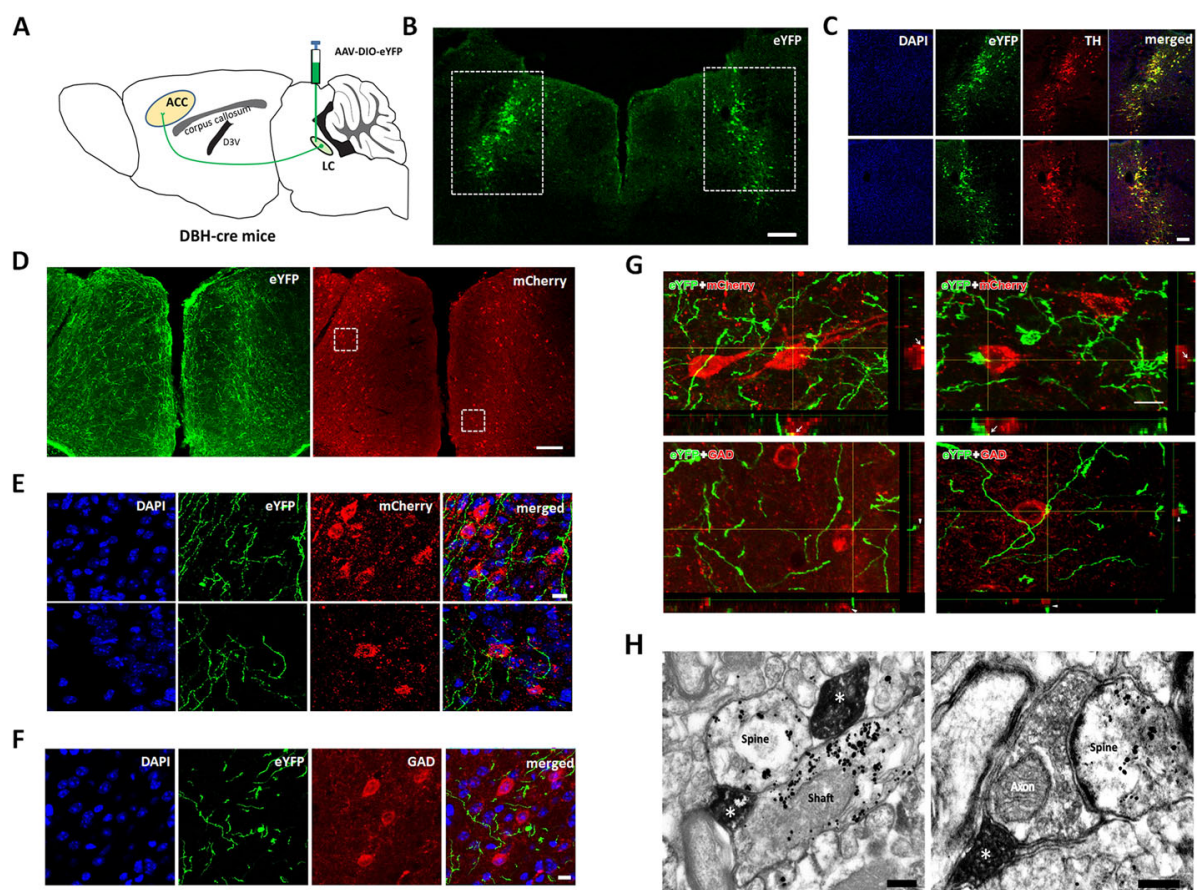

Fig. 1 Noradrenergic fibers from the LC project to the postsynaptic pyramidal cells in the ACC. a Diagram of AAV-DIO-eYFP injection and anterograde tracing strategy in the DBH-cre mice. $\mathbf{b}$ The AAV-DIO-eYFP injection sites in the LC. c AAV infected neurons in the rectangle areas of b are dual labeled with $\mathrm{TH}$ - immunopositivities. d Distribution of LC-ACC projecting NAergic fibers showing eYFP and the pyramidal cells infected by AAV-CaMKIla-mCherry in the ACC. e Enlarged figures in the rectangle areas in $\mathbf{d}$ showing LC-ACC projecting fibers (eYFP) made close connections with pyramidal cells (mcherry). f LC-ACC projecting NAergic fibers (eYFP) does not make close connection with GAD immunoreactive GABAergic neurons. $\mathbf{g}$ The 3D view of the close connections between eYFP labeled LC-ACC fibers and mcherry-labeled pyramidal cells or GAD-immunoreactive GABAergic neurons. $\mathbf{h}$ Two LC-ACC NAergic (eYFP immunoreactive with DAB) axon terminals (*) simultaneously make synapses with a dendritic spine and a shaft of a pyramidal cell (mcherry immunoreactive with nanogold) (left panel); One LC-ACC NAergic terminal (*) makes a synapse with a glutamatergic axon terminal, which in sequence makes a synapse with a spine of a pyramidal cell (right panel). Bars equals to $200 \mathrm{~nm}$ in $\mathbf{h}, 10 \mu \mathrm{m}$ in $\mathbf{e}, \mathbf{f}$ and $\mathbf{g}, 100 \mu \mathrm{m}$ in $\mathbf{C}$ and $200 \mu \mathrm{m}$ in $\mathbf{b}$ and $\mathbf{d}$

$(1 \mu \mathrm{M})$ or $\alpha 2$ receptor antagonist yohimbine $(1 \mu \mathrm{M})$ had no effect on NA induced enhancement of sEPSC (Fig. 2e-f). In addition, high doses of NA (50 and $100 \mu \mathrm{M})$ also induced an inward current. This inward current was blocked by prazosin, but not by yohimbine or propranolol (Fig. 3). To test if the effects of NA might be selective for excitatory transmission in the ACC, we examined inhibitory transmission as well. We found that neither the frequency nor the amplitude of the spontaneous inhibitory postsynaptic currents (sIPSCs), recorded from the pyramidal neurons, were changed by NA $(10 \mu \mathrm{M})$ application (Fig. 2g-h). This finding is in consistent with our morphological results and indicate that NA facilitates the presynaptic glutamate release to the pyramidal cells and enhances pyramidal cell membrane excitability, through distinct subtype receptors ( $\beta$ and $\alpha 1$ receptors, respectively).

The $\beta$ receptors and $\alpha 1$ receptors belong to members of the $\mathrm{G}$ protein-coupled receptor family (GPCR) and are associated with $\mathrm{Gs}$ and $\mathrm{Gq}$, respectively [45]. Since adenylyl cyclases (ACs) are important downstream molecules for Gs activation and closely associated with Gq activation induced calcium influx $[32,46]$, we tested whether NA-enhanced excitatory transmission would be affected in mice with gene deletion of $\mathrm{AC} 1$ or $\mathrm{AC} 8$ (AC1 and $\mathrm{AC} 8 \mathrm{KO}$ mice), which are the two major neuronal and calcium-stimulated subtypes of ACs [34, 47] (Fig. 4). Interestingly, the enhanced sEPSCs by NA $(10 \mu \mathrm{M})$ application was blocked in AC8 $\mathrm{KO}$ but not in AC1 $\mathrm{KO}$ mice (Fig. 4a-e). While the inward currents induced by application of $50 \mu \mathrm{M}$ of NA was significantly reduced in $\mathrm{AC} 1 \mathrm{KO}$ but not in AC8 $\mathrm{KO}$ mice (Fig. 4f-g). These results suggest that $\mathrm{AC} 8$ and $\mathrm{AC} 1$ contribute to pre- and post-synaptic downstream signalling for NA's effect on the excitatory transmission in ACC, respectively.

\section{In vivo study for NA's enhancement of ACC neuronal activities}

In vitro brain slice experiments indicate that NA enhances excitatory transmission in the ACC. Next, we wanted to know if focal electrical stimulation of the LC or NA microinjection into the ACC may enhance the neuronal activity in the ACC under in vivo condition (Fig. 5a). Spontaneous bursting activities were detected in the ACC neurons from anaesthetized rats. The firings from pyramidal neurons in the ACC were identified with the spike 

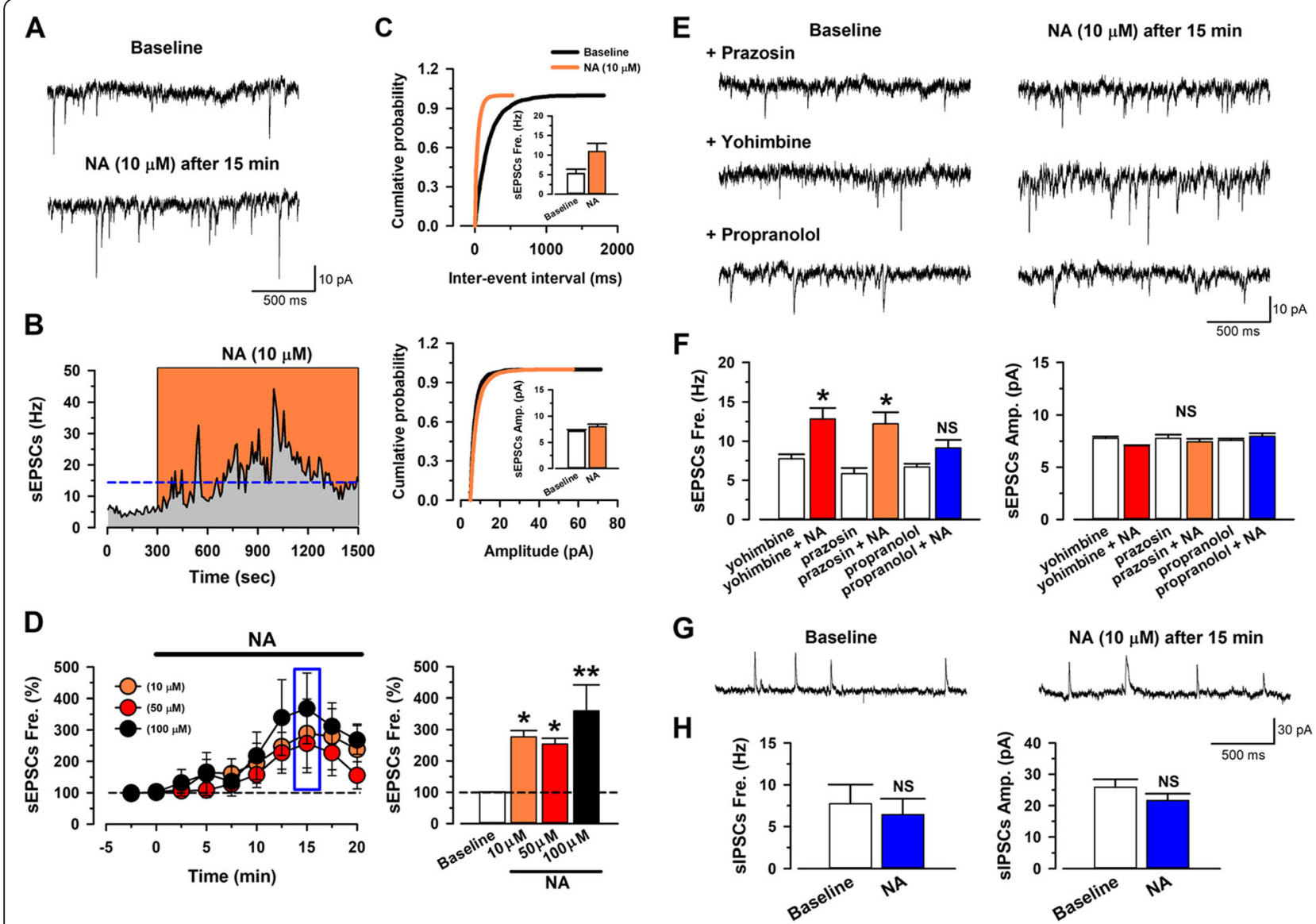

Fig. 2 Noradrenaline facilitates the spontaneous glutamatergic transmitter release in layer II/II pyramidal neurons in the adult mice ACC via $\beta$ receptor. a Raw trace of sEPSCs in baseline and NA $(10 \mu \mathrm{M})$ after $15 \mathrm{~min}$ application. $\mathbf{b}$ The histogram showing the frequency of sEPSCs of neuron in a. c Cumulative probability histogram and averaged results showing the frequency and amplitude of sEPSCs before and after NA (10 $\mu M)$ application. *, $p<0.05 ; \mathrm{ns}, p>0.05 . n=8$, Paired $t$-test. $\mathbf{d}$ Averaged results showing the frequency of sEPSCs are increased after NA (10, 50 or

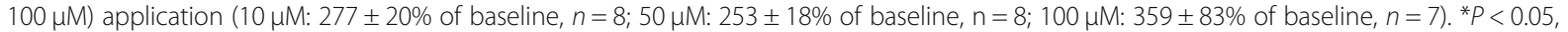
Baseline vs. NA $(10 \mu \mathrm{M}$ or $50 \mu \mathrm{M}),{ }^{*} P<0.01$, Baseline vs. NA $(100 \mu \mathrm{M})$, One-way ANOVA. e Sample traces of sEPSCs by NA $(10 \mu \mathrm{M})$ after 15 min in the presence of an a1 receptor antagonist prazosin $(1 \mu \mathrm{M})$, a 2 receptor antagonist yohimbine $(1 \mu \mathrm{M})$ or $\beta$ receptor antagonist propranolol $(1 \mu \mathrm{M})$. $\mathbf{f}$ The $\beta$ receptor antagonist, but not a1 receptor antagonist nor a 2 receptor antagonist blocks NA-induced enhanced frequency of sEPSCs (yohimbine: $7.75 \pm 0.56 \mathrm{~Hz}$; yohimbine + NA: $12.83 \pm 1.40 \mathrm{~Hz}, n=12$; prazosin: $5.86 \pm 0.71 \mathrm{~Hz}$; prazosin + NA: $12.21 \pm 1.48 \mathrm{~Hz}, n=10$; propranolol: $6.69 \pm 0.42 \mathrm{~Hz}$; propranolol $+\mathrm{NA} ; 9.13 \pm 1.03 \mathrm{~Hz}, \mathrm{n}=10) .{ }^{*} P<0.05$, yohimbine vs. yohimibine $+\mathrm{NA}$; prazosin vs. prazosin + NA (left panel). NS indicates no statistical significance between propranolol and propranolol + NA. Receptor antagonists do not change the averaged amplitude of sEPSCs (yohimbine: $7.77 \pm 0.17 \mathrm{pA}$; yohimbine + NA: $7.06 \pm 0.06 \mathrm{pA}, \mathrm{n}=12$; prazosin: $7.77 \pm 0.35 \mathrm{pA}$; prazosin + NA: $7.44 \pm 0.28 \mathrm{pA}, \mathrm{n}=10$; propranolol: $7.57 \pm 0.17 \mathrm{pA}$; propranolol $+\mathrm{NA} ; 7.96 \pm 0.29 \mathrm{pA}, \mathrm{n}=10$ ) (right panel). Paired t-test. $\mathbf{g}$ Sample traces of sIPSCs in baseline (left) and NA (10 $\mu \mathrm{M}$, right) after $15 \mathrm{~min}$ application. $\mathbf{h}$ Averaged frequency (Baseline: $7.73 \pm 2.30 \mathrm{~Hz}$; NA: $6.44 \pm 1.88 \mathrm{~Hz}, n=5$; left panel) and amplitude (Baseline: $25.84 \pm 2.56$ pA; NA: $21.63 \pm 2.18$ pA, $n=5$; right panel) of sIPSCs before and after NA application. NS indicates no statistical significance among the groups. Paired $t$-test

width, as we reported previously [40]. We found that electrical stimulation of the $\mathrm{LC}$ increased the number of spikes in the ACC (Fig. 5b, d and h). Similar results were found with NA $(50 \mu \mathrm{g} / 0.5 \mu \mathrm{L})$ microinjection into the ACC (Fig. $5 c, d$ and $h$ ). Because $\beta$ and $\alpha 1$ receptors are critical for the ACC excitation in vitro, we injected $\beta$ receptor agonist Isoproterenol $(37 \mu \mathrm{g} / 0.5 \mu \mathrm{L})$ or $\alpha 1$ receptor agonist Phenylephrine $(5 \mu \mathrm{g} / 0.5 \mu \mathrm{L})$ into the ACC. We found that microinjection of the agonists enhanced the firing frequency during bursting activities (Fig. 5e-h).

\section{Optostimulation of LC-ACC pathways}

The NAergic effect on ACC neurons were then further confirmed by selectively activating the LC-ACC NAergic projection by Cre-dependent optostimulation. Bilateral LCs were infected by injecting AAV-DIO-ChR2(H134R)-eYFP in $\mathrm{DBH}$-cre mice. The NA projecting fibers in the ACC were optostimulated by low $(5 \mathrm{~Hz})$ or high $(20 \mathrm{~Hz})$ frequency of blue light $(470 \mathrm{~nm})$ after ACC slices were prepared from infected mice (Fig. 6a). We found that both 5 and $20 \mathrm{~Hz}$ optostimulation for $1 \mathrm{~min}$ increased the frequency of the sEPSCs on the recorded pyramidal cells in 


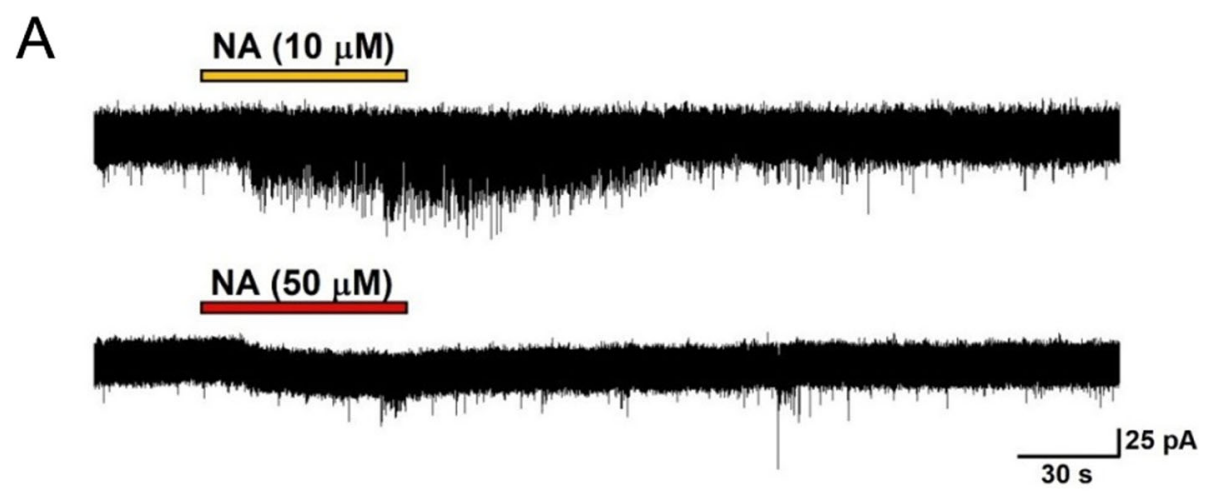

B

\section{Prazosin}
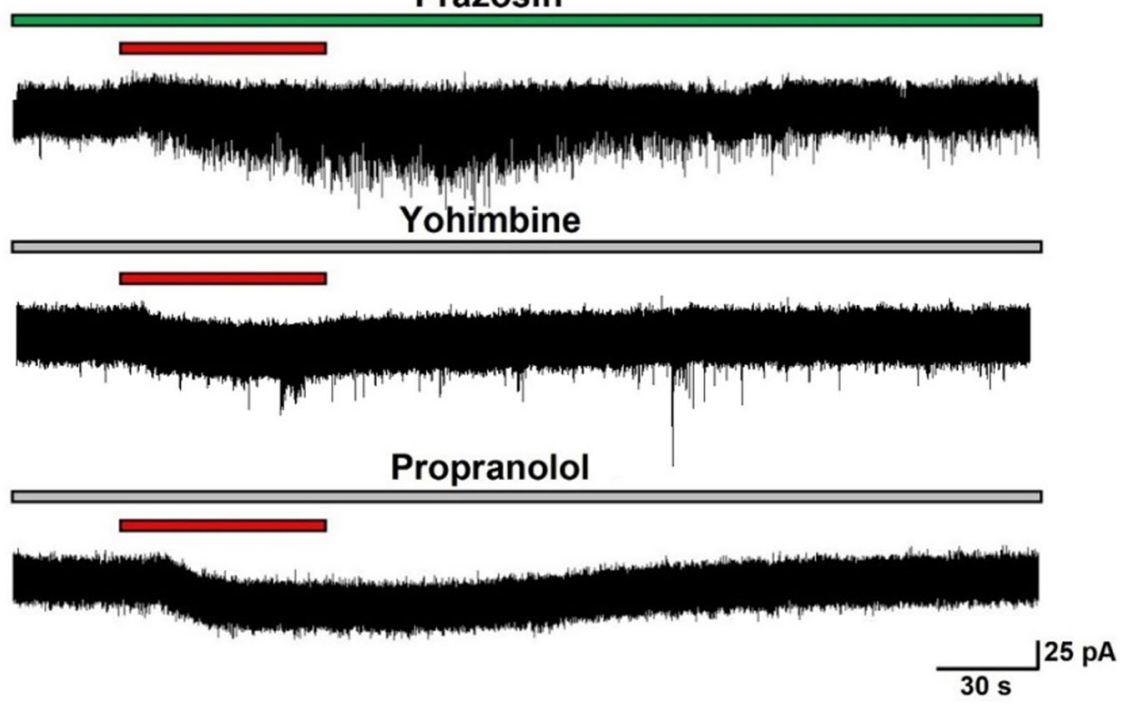

C

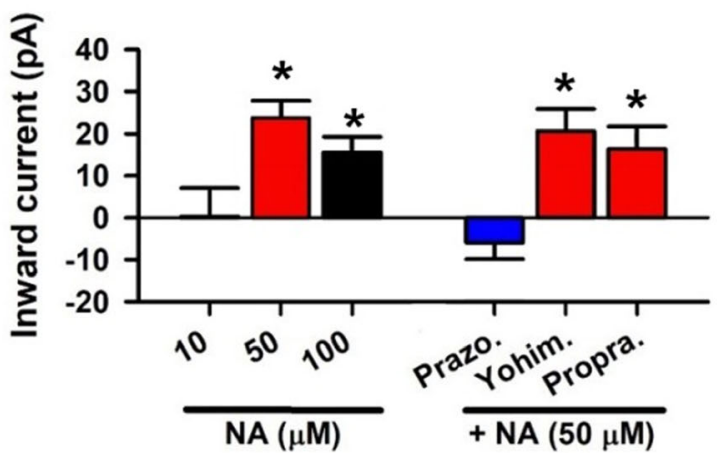

Fig. 3 Noradrenaline induced inward current in pyramidal cells via a1 receptor. a Samples showing High dose (50 $\mu \mathrm{M})$ but not low dose (10 $\mu \mathrm{M})$ of NA produced inward currents. $\mathbf{b}$ Samples showing a1 receptors antagonist prazosin, but not a2 receptors antagonist yohimbine nor $\beta 1$ receptors antagonist propranolol blocked the inward current induced by NA $(50 \mu \mathrm{M})$. C , Averaged results showing high dose but not low dose of NA induced inward current (10 $\mu \mathrm{M}$ NA: $n=13,50 \mu \mathrm{M}$ NA: $n=12,100 \mu \mathrm{M}$ NA: $n=12)$. The inward currents were blocked by a1 receptors antagonist, but not a2 receptors nor $\beta$ receptors antagonist. High dose of NA $(50 \mu \mathrm{M})$ produced inward current is blocked by Prazosin (10 $\mu \mathrm{M}$ NA: $0.34 \pm 3.74$ pA, $n=13 ; 50 \mu M$ NA: $23.73 \pm 4.13$ pA, $n=12 ; 100 \mu M$ NA: 15.69 pA \pm 3.82 pA, $n=12$; Prazosin:: $-5.94 \pm 3.76$ pA, $n=9$; Yohimbine: $20.58 \pm 4.59$ pA,$n=8$; Propranolol: $16.35 \pm 4.79 \mu \mathrm{pA}, \mathrm{n}=8$ ). ${ }^{*} P<0.05,10 \mu \mathrm{M}$ NA vs. $50 \mu \mathrm{M}$ or $100 \mu \mathrm{M}$ NA, Prazosin vs. Yohimbine or Propranolol. One-Way ANOVA 


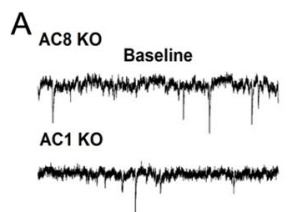

B
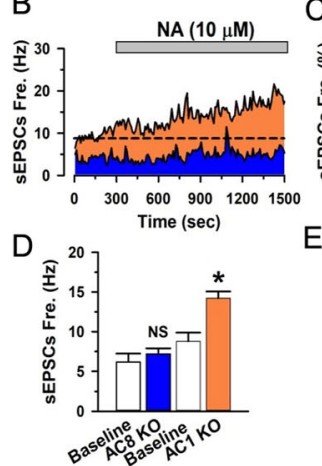

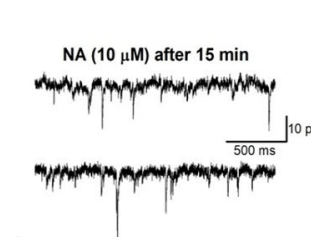

C

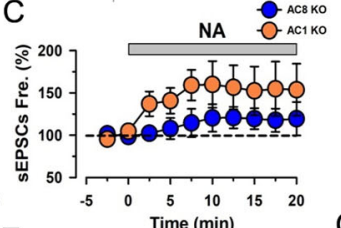

E

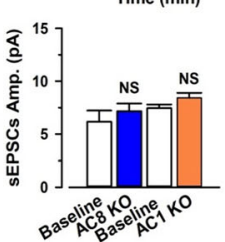

$\mathrm{F}$

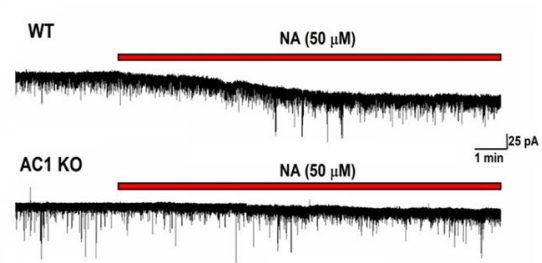

AC8 Ko

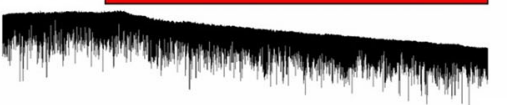

G

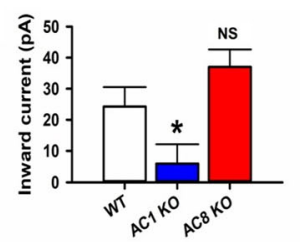

Fig. $4 \mathrm{NA}$ induced enhancement of glutamatergic transmission is blocked in different type of adenylyl cyclase knockout mice. a Sample traces of

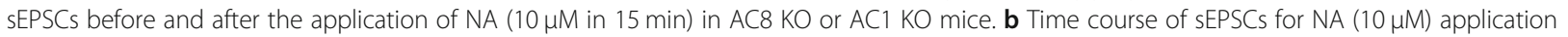
in sample neurons of an AC8 or AC1 KO mice. c Averaged time course of sEPSCs for NA application from AC8 KO or AC1 KO mice. $\mathbf{d}$ Averaged frequency of sEPSCs with application of NA in AC8 KO or AC1 KO mice (Baseline in AC8 KO mice: $6.17 \pm 1.05 \mathrm{~Hz} ; \mathrm{AC} 8 \mathrm{KO}$ mice: $7.17 \pm 0.73 \mathrm{~Hz}, n=$ 7; Baseline in AC1 KO mice: $8.79 \pm 1.08 \mathrm{~Hz}$; AC1 KO mice: $14.22 \pm 0.85 \mathrm{~Hz}, n=6$.). NS indicates no statistical significance between Baseline and AC8 $\mathrm{KO}$ mice. ${ }^{*} P<0.05$, baseline vs. AC1 KO. Paired t-test. e Averaged amplitude of sEPSCs with application of NA in AC8 KO or AC1 KO mice (Baseline in AC8 KO mice: $7.75 \pm 0.11$ pA; AC8 KO mice: $8.21 \pm 0.47 \mathrm{pA}, \mathrm{n}=7$; Baseline in AC1 KO mice: $7.46 \pm 0.35 \mathrm{pA}$; AC1 KO mice; $8.43 \pm 0.46 \mathrm{pA}, \mathrm{n}=6$ ). NS indicates no statistical significance between Baseline and AC8 KO mice or AC1 KO mice. Paired $t$-test. $\mathbf{f}$ Sample traces showing NA could induce inward currents in WT and AC8 KO mice but not in AC1 KO mice. G, The summarized data showing NA induced inward currents in WT or AC8 KO but not AC1 KO mice (WT: 21.28 $\pm 6.23 \mathrm{pA}, n=16$; AC1 KO mice: $6.01 \pm 6.13 \mathrm{pA}, n=8$, AC8 KO mice: $37.013 \pm 5.63 \mathrm{pA}, \mathrm{n}=8)$. ${ }^{*} P<0.05$, $A C 1 \mathrm{KO}$ vs. WT and AC1 vs. AC8 KO mice. NS indicates no statistical significance between Baseline and AC8 KO mice. One-Way ANOVA

the ACC, without changing the amplitude of sEPSCs (Fig. 6b-d). However, only $20 \mathrm{~Hz}$ but not $5 \mathrm{~Hz}$ optostimulation induced obvious inward current (Fig. 6b, c and e), similar to the requirement of high doses of NA for producing postsynaptic effects. Furthermore, the facilitation effect on the frequency of sEPSCs was totally blocked by propranolol and the induced inward current was blocked by prazosin. Consistent results from both rats and mice indicate the NA induced facilitation effect is unlikely specie dependent.

The sIPSCs of the pyramidal cells and sEPSCs of the interneurons were also recorded. However, 5 and $20 \mathrm{~Hz}$ optostimulation neither changed the frequency and amplitude of the sIPSCs or sEPSCs, nor induced inward or outward currents, of the pyramidal cells or interneurons (Fig. 6f-i). Considering that the sEPSCs were enhanced and the inward currents were induced in pyramidal cells, we proposed that the difference may be in part due to distinct distribution of the $\beta$ and $\alpha 1$ receptors in pyramidal cells and interneurons.

\section{Stimulation of LC-ACC pathway induced behavioural responses}

Our in vivo and in vitro results consistently indicate that NAergic LC-ACC projection potentiatesexcitatory synaptic transmission in the ACC. Considering the importance of ACC neurons in the sensory process of pain and itch, we liked to examine the behavioral effects after optostimulating the NAergic LC-ACC projection in vivo. In $\mathrm{DBH}$-Cre mice with $\mathrm{ChR} 2$ infection of bilateral LCs, optic cannula was implanted in the ACC and the animals basal behaviors were evaluated after $470 \mathrm{~nm}$ optostimulation were applied (Fig. 7a) [15]. The distribution of Fos protein in the ACC strongly suggest that opto-stimulation is limited within ACC (Fig. 7b). We found that, after the optostimulation, both scratching with the hind paws and wiping with the fore paws on animal's face and head were observed (Fig. 7c-d). The scratching behavior has been proposed to link to itching responses and wiping behavior has linked to nociceptive responses, respectively [48]. We further tested the paw withdrawal threshold by von Frey filament stimulation on animals' hind paws. The mechanical thresholds were significantly decreased after $20 \mathrm{~Hz}$ optostimulation (Fig. $7 \mathrm{e})$. On the contrary, in control mice with AAV-DIOeYFP injection, $20 \mathrm{~Hz}$ optostimulation did not produce similar effects (Fig. 7c-e).

\section{Discussion}

Noradrenergic projections from the LC to the CNS have been implicated in many key brain functions, such as 


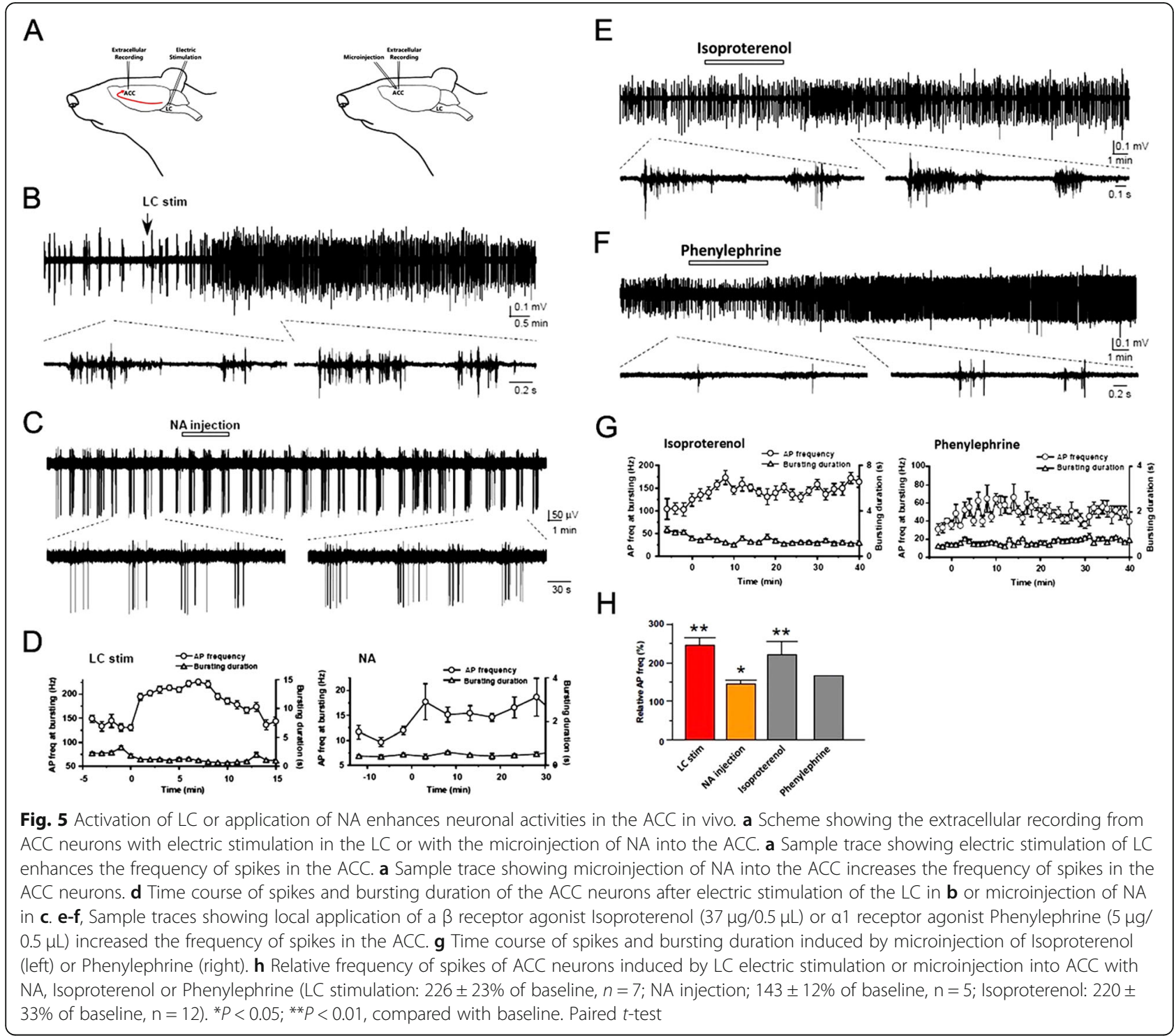

attention, arousal, learning and memory [1, 2, 49, 50]. Our present studies reveal a novel function of NAergic projection from LC to ACC, an important cortical region for the regulation of sensory process $[20,22$, $23,51]$. On the contrary to the well-known inhibitory effect of sensory transmission at the spinal level, NA's effect on ACC seems to facilitate the sensory process. In the situation encounters noxious stimuli (that causes pain sensation), activation of NAergic LCspinal pathway will reduce the amount of nociceptive inputs to the spinal cord [17-19] but enhance the nociceptive responses in the brain.

The LC sends descending NAergic projections to the spinal cord [52], which is a major inhibitory pathway and alleviates chronic pain in the spinal cord $[6,13,14]$. This inhibitory effect is mainly mediated by $\alpha_{2 \mathrm{~A}}$ receptors, which are located on afferent axon inputs in the superficial laminae [53], and $\alpha_{2 C}$ receptors, which are located on glutamatergic interneurons, in spinal dorsal horn [54]. Meanwhile, NA enhances neural excitability in GAD67 expressing interneurons in the laminae II through activation of $\alpha 1$ receptor [16]. One in vivo electrophysiological experiment provides direct evidence showing the inhibitory effect of NA in spinal level, in which optogenetic stimulation of the LC-spinal cord pathway facilitates inhibitory transmissions in the superficial dorsal horn neurons [8]. This inhibition is likely mediated by both reducing the excitatory nociceptive inputs and activation of local inhibitory interneurons.

Different from the well-known descending inhibition for nociception, the effect of LC-cortical ascending pathway in pain sensation is not clear yet. Recently, 


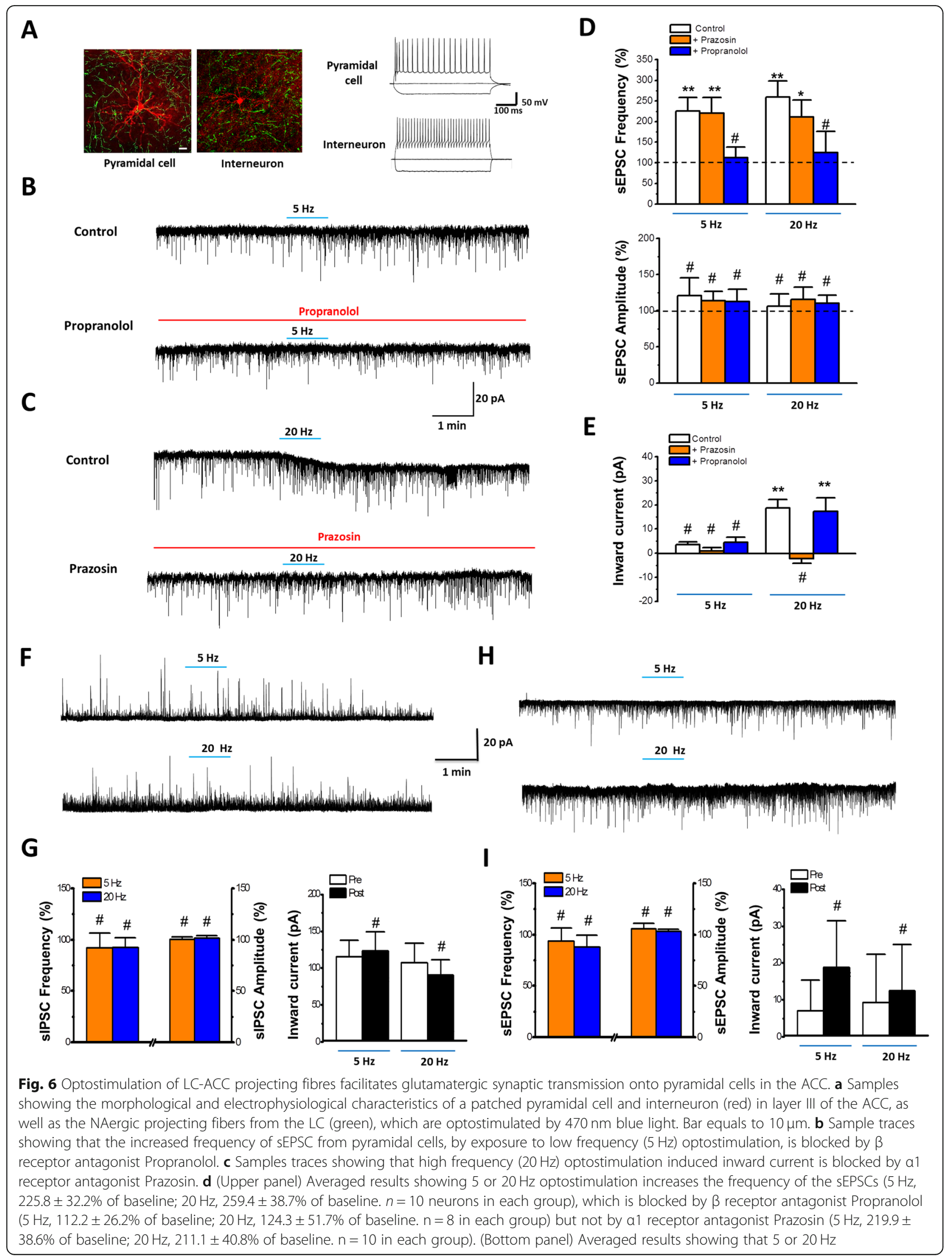




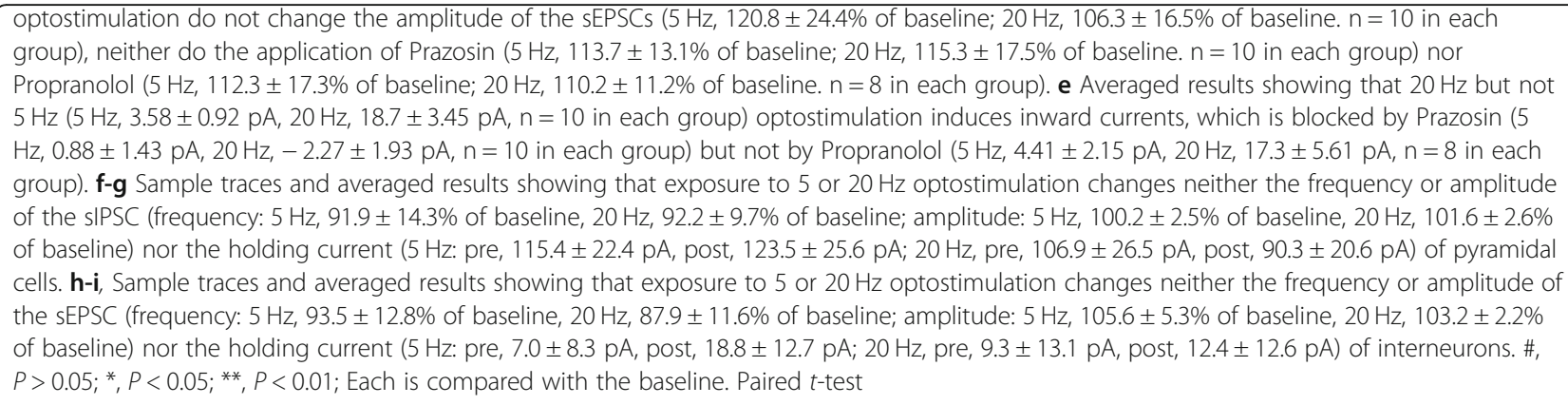

Hirschberg et al., show that activation of LC-prefrontal cortex (PFC) induces aversion and anxiety and exacerbated spontaneous pain in neuropathic pain rats. However, the mechanism for the LC-PFC ascending regulation is not investigated [55]. In the present study, we found that NA from LC-ACC enhanced the excitatory transmission in the ACC, through $\alpha 1$ and $\beta$ receptors. Light and electron microscopic observation combined with Cre-dependent tracing method provided morphological evidence that the ascending NAergic projections from LC predominately terminated on the pyramidal neurons but not interneurons in the ACC. Functionally, bath application of NA enhanced presynaptic glutamatergic synaptic transmission to and postsynaptic cellular excitability of layer II/III pyramidal neurons, through $\beta$ and $\alpha 1$ receptors respectively. This is confirmed by optogenetic stimulation of LC-ACC projections. Additional in vivo unit recordings confirmed that electrical stimulating of the LC or local application of NA enhanced neural activity in the ACC. Therefore, the different mechanisms between descending inhibition and ascending facilitation pathway from the LC may be due to the different types of NAergic receptors and target neurons in the spinal cord and the cortex.

An interesting role of NA in the ACC was that NA played different effects in a dose-dependent manner. Low dose of NA or low frequency optostimulation to LC-ACC fibers strongly increased the release of glutamate to layer II/III pyramidal cells in the ACC. On the other hand, high dose of NA or high frequency optostimulation, in addition to increased glutamate release, induced inward current in recorded pyramidal cells. It's also shown that the increased glutamate release was mediated by $\beta$ receptor and the induced inward current was mediated by $\alpha 1$ receptor. Using $A C 1$ or AC8 $\mathrm{KO}$ mice, we confirmed that the enhanced release of glutamate was blocked in AC8 $\mathrm{KO}$ mice and the induced inward current was blocked in $\mathrm{AC} 1 \mathrm{KO}$ mice. Thus, the facilitatory effect produced by NA in ACC may be mediated by presynaptic $\beta$ receptor-AC8 signaling pathway and post-synaptic $\alpha 1$ receptor-AC1 signaling pathway, respectively. This finding is in consistent with our previous works, in which we have confirmed that AC-cAMP signaling pathways are involved in different forms of pain in the ACC [24, 34, 56, 57]. In the present study, except for the mechanical hypersensitivity effect, we found that the scratching behavior were enhanced after activating the NAergic projection fibers. Thus, activations of AC-cAMP signaling pathway may not be limited for the regulation of nociceptive information. It is more likely that the pathway is involved with the hypersensitivity for both pain and itching-like sensory information.

It is known that the ACC plays critical roles in both pain and itch in from rodents to human [28, 30, 51]. In animal study, nociceptive stimulation at the hindpaw increases neural activity in the ACC in vivo [58]. Animal models of chronic pain enhance glutamatergic transmission within the ACC $[51,59,60]$. In addition, itch stimulation also increases glutamatergic transmissions in the ACC [30, 61]. Interestingly, activations of pyramidal neurons by optogenetic stimulations within the ACC enhance both pain and itch behaviors [26, 31]. However, it is unclear whether pain and itch information share the common pathway in the CNS under physiological and pathophysiologic conditions. How does activation of NA from the $\mathrm{LC}$ in the $\mathrm{ACC}$ regulate pain and itch functions is not investigated before. However, according to our results, NA may modulate both pain and itch pathway within the ACC by altering glutamatergic transmissions. Further study is certainly needed for understanding the mechanism of how NA modulate these two different sensations in detail.

In sum, we find that NAergic LC-ACC projection facilitates the excitatory synaptic transmission to pyramidal cells in the ACC and enhance the itch and pain like responses in animals. This LC-ACC ascending projection may help animals or humans to enhance behavioral responses to injury, and alert themselves from dangerous situation. It may also help to form long-term memory at cortical synapses [50], which is beneficial for human or animals to gain new knowledge from potentially dangerous information. 
A

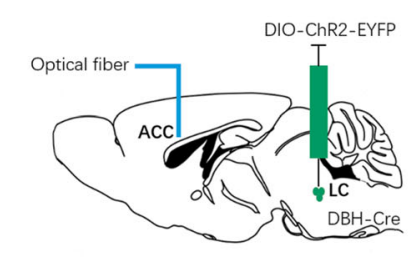

C

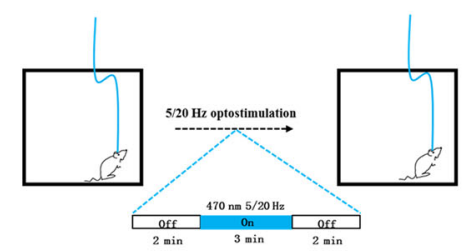

D
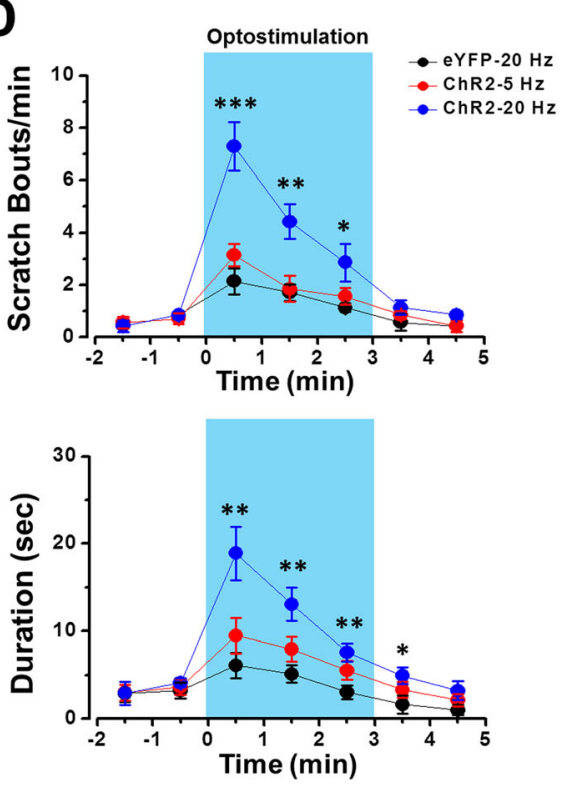

$\mathbf{F}$

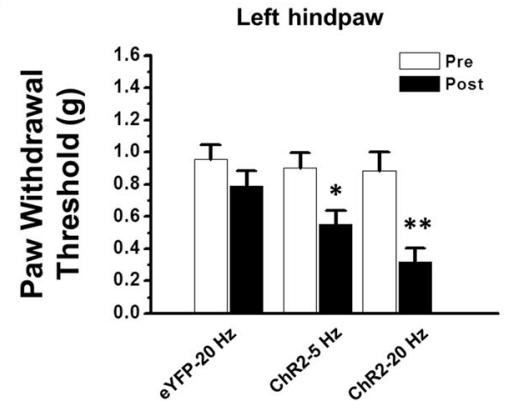

B
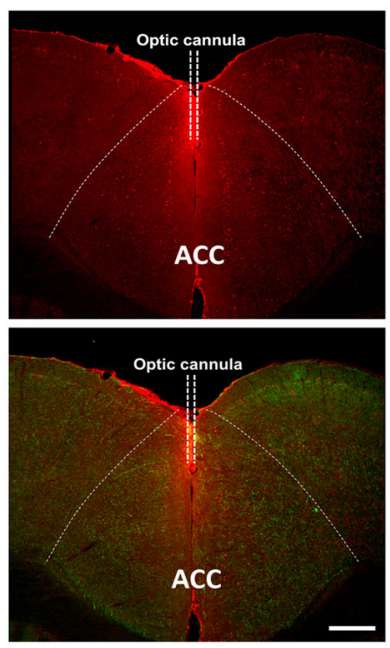

E
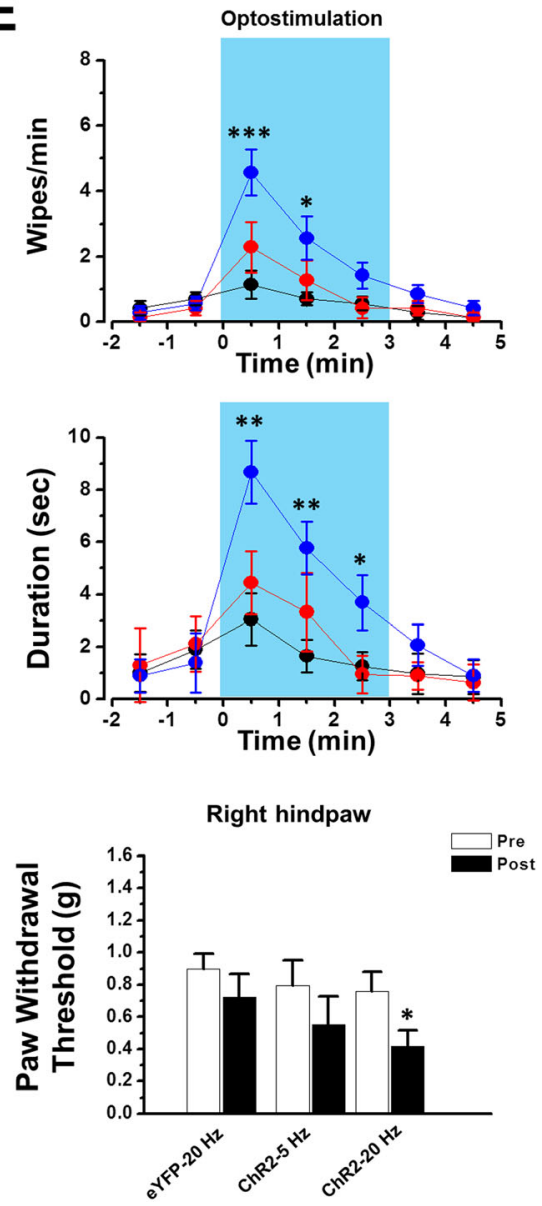

Fig. 7 (See legend on next page.) 
(See figure on previous page.)

Fig. 7 Activation of LC-ACC pathway facilitates the itch and pain sensations. a Diagram of stereotaxic virus injection into the LC of DBH-Cre mice and optic cannula implantation in the ACC. $\mathbf{b}$ Figures showing that optostimulation of the LC-ACC projecting NAergic fibers (Green) through the optic cannula induced strong Fos expression (Red) within the ACC. c Experimental schema of behaviour test. $\mathbf{d}$ The bouts and duration of scratching are increased after in vivo optostimulation in mice with ChR2 infection. ${ }^{*} P<0.05,{ }^{* *}, P<0.01,{ }^{* * *}, P<0.001$, in comparison with eYFP$20 \mathrm{~Hz}$ group ( $\mathrm{n}=7$ mice in each group). Two-Way ANOVA. $\mathbf{e}$ The number and duration of wiping are increased after in vivo optostimulation. ${ }^{*}$ $P<0.05,{ }^{* *}, P<0.01,{ }^{* * *}, P<0.001$, in comparison with eYFP-20 Hz group. Two-Way ANOVA. $\mathbf{f}$ The paw withdrawal thresholds are decreased in both left and right hind paws after optostimulation (left hindpaw: eYFP-20 Hz: pre, $0.96 \pm 0.09 \mathrm{~g}$, post, $0.79 \pm 0.09 \mathrm{~g}, P>0.05$; ChR2-5 Hz: pre, $0.90 \pm 0.10 \mathrm{~g}$, post, $0.55 \pm 0.08 \mathrm{~g}, P<0.05 ;$ ChR2 $-20 \mathrm{~Hz}$ : pre, $0.88 \pm 0.12 \mathrm{~g}$, post, $0.32 \pm 0.09 \mathrm{~g}, P<0.01$; right hindpaw: eYFP- $20 \mathrm{~Hz}$ : pre, $0.90 \pm 0.09 \mathrm{~g}$, post, $0.73 \pm 0.14 \mathrm{~g}, P>0.05$; ChR2-5 Hz: pre, $0.80 \pm 0.16 \mathrm{~g}$, post, $0.55 \pm 0.17, P>0.05$; ChR2-20 Hz: pre, $0.76 \pm 0.12 \mathrm{~g} ;$ post, $0.42 \pm 0.10 \mathrm{~g}, P<0.05 . n=$ 6 mice in each group). Paired $t$-test

\section{Abbreviations}

AC: Adenylyl cyclase; ACC: Anterior cingulate cortex; ACSF: Artificial cerebrospinal fluid; CNS: Central nervous system; IC: Insular cortex; KO: Knockout; LC: Locus coeruleus; NA: Noradrenaline; PFC: Prefrontal cortex sEPSCs: Spontaneous excitatory post-synaptic currents; sIPSCs: Spontaneous inhibitory postsynaptic currents

\section{Acknowledgments}

We thank Melissa Lepp for proof-reading and editing.

\section{Authors' contributions}

$\mathrm{KK}, \mathrm{AY}, \mathrm{XHL}, \mathrm{QYC}$ and RHL performed in vitro electrophysiological experiments; AY and HF examined in vivo electrophysiology; QS, CZ, TC and JG studied optogenetic and anatomical works; KK, AY and TC drafted the manuscript; KK, HF, MZ, and TC designed and finished the final vision of the manuscript. The authors read and approved the final manuscript.

\section{Funding}

M. Z. was supported by Grants36 from the Canadian Institute for Health Research (CIHR) project Grants (PJT-148648 and 419286). K.K. is supported in part by JSPS KAKENHI Grant Numbers JP 17 H05074 and JP 17 K19879, Takeda Science Foundation and Hyogo Innovative Challenge. H.F. is supported in part by JSPS KAKENHI Grant Numbers JP 17 H04114 and JP 16 K15341. T.C. is supported by National Natural Science Foundation of China (81671095) and Foundation for Distinguished Young Scholar of ShaanXi (2019JC-21). J. G. is supported by National Natural Science Foundation of China (81701093).

\section{Availability of data and materials}

The data that support the findings of this study are available from the corresponding author upon reasonable request.

\section{Ethics approval}

All animal experiments were done in accordance with the Animal Care and Use Committee at the Air Force Medical University and Xian Jiaotong University in China, National Institutes of Natural Sciences in Japan and Hyogo College of Medicine approved the experimental protocols.

\section{Consent for publication}

Not applicable.

\section{Competing interests}

The authors declare that they have no competing interests.

\section{Author details}

${ }^{1}$ Center for Neuron and Disease, Frontier Institute of Science and Technology, Xi'an Jiaotong University, Xi'an 710049, China. ${ }^{2}$ Department of Physiology, Faculty of Medicine, University of Toronto, Medical Science Building, 1 King's College Circle, Toronto, Ontario M5S 1A8, Canada. ${ }^{3}$ Department of Neurophysiology, Hyogo College of Medicine, Nishinomiya 663-8501, Japan. ${ }^{4}$ Department of Anatomy, Histology \& Embryology, Air Force Medical University, Xi'an 710032, China. ${ }^{5}$ National Institute of Biological Sciences, Beijing 102206, China. ${ }^{6}$ Tsinghua Institute of Multidisciplinary Biomedical Research, Tsinghua University, Beijing 102206, China.
Received: 13 January 2020 Accepted: 11 March 2020

Published online: 26 March 2020

\section{References}

1. Sara SJ. The locus coeruleus and noradrenergic modulation of cognition. Nat Rev Neurosci. 2009:10:211-23 Review.

2. Sara SJ, Bouret S. Orienting and reorienting: the locus coeruleus mediates cognition through arousal. Neuron. 2012;76:130-41 Review.

3. Aston-Jones G, Cohen JD. An integrative theory of locus coeruleusnorepinephrine function: adaptive gain and optimal performance. Annu Rev Neurosci. 2005;28:403-50.

4. Rodenkirch C, Liu Y, Schriver BJ, Wang Q. Locus coeruleus activation enhances thalamic feature selectivity via norepinephrine regulation of intrathalamic circuit dynamics. Nat Neurosci. 2019;22:120-33.

5. Uematsu A, Tan BZ, Ycu EA, Cuevas JS, Koivumaa J, Junyent F, et al. Modular organization of the brainstem noradrenaline system coordinates opposing learning states. Nat Neurosci. 2017;20:1602-11.

6. McMahon S, Koltzenburg M. Wall and Melzack's textbook of pain. New York: Elsevier Academic Press; 2013.

7. North RA, Yoshimura M. The actions of noradrenaline on neurones of the rat substantia gelatinosa in vitro. J Physiol. 1984;349:43-55.

8. Yoshimura M, Furue $\mathrm{H}$. In vivo electrophysiological analysis of mechanisms of monoaminergic pain inhibitory systems. Pain. 2017:158(Suppl 1):S85-s91.

9. Gebhart GF. Descending modulation of pain. Neurosci Biobehav Rev. 2004:27:729-37.

10. Llorca-Torralba M, Borges G, Neto F, Mico JA, Berrocoso E. Noradrenergic locus Coeruleus pathways in pain modulation. Neuroscience. 2016;338:93-113.

11. Bannister K, Dickenson AH. The plasticity of descending controls in pain: translational probing. J Physiol. 2017;595:4159-66.

12. Zhuo M. Descending facilitation. Mol Pain. 2017:13:1744806917699212.

13. Luo C, Kuner T, Kuner R. Synaptic plasticity in pathological pain. Trends Neurosci. 2014;37:343-55.

14. Sandkuhler J, Gruber-Schoffnegger D. Hyperalgesia by synaptic long-term potentiation (LTP): an update. Curr Opin Pharmacol. 2012;12:18-27.

15. Chen T, Taniguchi W, Chen QY, Tozaki-Saitoh H, Song Q, Liu RH, et al. Topdown descending facilitation of spinal sensory excitatory transmission from the anterior cingulate cortex. Nat Commun. 2018;9:1886.

16. Gassner M, Ruscheweyh $R$, Sandkuhler J. Direct excitation of spinal GABAergic interneurons by noradrenaline. Pain. 2009;145:204-10.

17. Westlund KN, Zhang D, Carlton SM, Sorkin LS, Willis WD. Noradrenergic innervation of somatosensory thalamus and spinal cord. Prog Brain Res. 1991;88:77-88

18. Sandkuhler J. The organization and function of endogenous antinociceptive systems. Prog Neurobiol. 1996;50:49-81.

19. Jones SL. Descending noradrenergic influences on pain. Prog Brain Res. 1991;88:381-94

20. Vogt BA. Pain and emotion interactions in subregions of the cingulate gyrus. Nat Rev Neurosci. 2005;6:533-44.

21. Schwarz LA, Miyamichi K, Gao XJ, Beier KT, Weissbourd B, DeLoach KE, et al. Viral-genetic tracing of the input-output organization of a central noradrenaline circuit. Nature. 2015;524:88-92.

22. Bushnell MC, Ceko M, Low LA. Cognitive and emotional control of pain and its disruption in chronic pain. Nat Rev Neurosci. 2013;14:502-11.

23. Bliss TV, Collingridge GL, Kaang BK, Zhuo M. Synaptic plasticity in the anterior cingulate cortex in acute and chronic pain. Nat Rev Neurosci. 2016;17:485-96.

24. Zhuo M. Neural mechanisms underlying anxiety-chronic pain interactions. Trends Neurosci. 2016;39:136-45. 
25. Kim SS, Wang H, Li XY, Chen T, Mercaldo V, Descalzi G, et al. Neurabin in the anterior cingulate cortex regulates anxiety-like behavior in adult mice. Mol Brain. 2011;4:6.

26. Kang SJ, Kwak C, Lee J, Sim SE, Shim J, Choi T, et al. Bidirectional modulation of hyperalgesia via the specific control of excitatory and inhibitory neuronal activity in the ACC. Mol Brain. 2015;8:81.

27. Calejesan AA, Kim SJ, Zhuo M. Descending facilitatory modulation of a behavioral nociceptive response by stimulation in the adult rat anterior cingulate cortex. Eur J Pain. 2000;4:83-96.

28. Mochizuki H, Sadato N, Saito DN, Toyoda H, Tashiro M, Okamura N, et al. Neural correlates of perceptual difference between itching and pain: a human fMRI study. Neuroimage. 2007;36:706-17.

29. Ikoma A, Steinhoff M, Ständer S, Yosipovitch G, Schmelz M. The neurobiology of itch. Nat Rev Neurosci. 2006;7:535-47.

30. Descalzi G, Chen T, Koga K, Li XY, Yamada K, Zhuo M. Cortical GluK1 kainate receptors modulate scratching in adult mice. J Neurochem. 2013;126:636-50.

31. Lu YC, Wang YJ, Lu B, Chen M, Zheng P, Liu JG. ACC to dorsal medial striatum inputs modulate histaminergic itch sensation. J Neurosci. 2018;38:3823-39.

32. Wong ST, Athos J, Figueroa XA, Pineda W, Schaefer ML, Chavkin CC, et al. Calcium-stimulated adenylyl cyclase activity is critical for hippocampusdependent long-term memory and late phase LTP. Neuron. 1999;23:787-98.

33. Schaefer ML, Wong ST, Wozniak DF, Muglia LM, Liauw JA, Zhuo M, et al. Altered stress-induced anxiety in adenylyl cyclase type VIII-deficient mice. J Neurosci. 2000;20:4809-20.

34. Wei F, Qiu CS, Kim SJ, Muglia L, Maas JW, Pineda W, et al. Genetic elimination of behavioral sensitization in mice lacking calmodulinstimulated adenylyl cyclases. Neuron. 2002;36:713-26.

35. Koga K, Descalzi G, Chen T, Ko HG, Lu J, Li S, et al. Co-existence of two forms of LTP in ACC provides a synaptic mechanism for the interactions between anxiety and chronic pain. Neuron. 2015;85:377-89.

36. Zhao MG, Toyoda H, Lee $Y$, Wu L, Ko S, Zhang $X$, et al. Roles of NMDA NR2B subtype receptor in prefrontal long-term potentiation and contextual fear memory. Neuron. 2005;47:859-72.

37. Li XY, Ko HG, Chen T, Descalzi G, Koga K, Wang H, et al. Alleviating neuropathic pain hypersensitivity by inhibiting PKMzeta in the anterior cingulate cortex. Science. 2010;330:1400-4.

38. Furue $\mathrm{H}$. In vivo blind patch-clamp recording technique. Tokyo, London, New York: Springer; 2012

39. Funai $Y$, Pickering AE, Uta D, Nishikawa K, Mori T, Asada A, et al. Systemic dexmedetomidine augments inhibitory synaptic transmission in the superficial dorsal horn through activation of descending noradrenergic control: an in vivo patch-clamp analysis of analgesic mechanisms. Pain. 2014;155:617-28.

40. Steenland HW, Li XY, Zhuo M. Predicting aversive events and terminating fear in the mouse anterior cingulate cortex during trace fear conditioning. J Neurosci. 2012:32:1082-95.

41. Sugiyama D, Hur SW, Pickering AE, Kase D, Kim SJ, Kawamata M, et al. In vivo patch-clamp recording from locus coeruleus neurones in the rat brainstem. J Physiol. 2012;590:2225-31.

42. Cedarbaum JM, Aghajanian GK. Activation of locus coeruleus neurons by peripheral stimuli: modulation by a collateral inhibitory mechanism. Life Sci. 1978;23:1383-92

43. Zhang F, Wang LP, Brauner M, Liewald JF, Kay K, Watzke N, et al. Multimodal fast optical interrogation of neural circuitry. Nature. 2007;446:633-9.

44. Madisen L, Mao T, Koch H, Zhuo JM, Berenyi A, Fujisawa S, et al. A toolbox of Cre-dependent optogenetic transgenic mice for light-induced activation and silencing. Nat Neurosci. 2012;15:793-802.

45. Poyner DR, Wheatley M. G protein-coupled receptors: essential methods; 2010.

46. Ferrero JJ, Alvarez AM, Ramirez-Franco J, Godino MC, Bartolome-Martin D, Aguado C, et al. Beta-adrenergic receptors activate exchange protein directly activated by CAMP (Epac), translocate Munc13-1, and enhance the Rab3A-RIM1alpha interaction to potentiate glutamate release at cerebrocortical nerve terminals. J Biol Chem. 2013:288:31370-85.

47. Xia Z, Storm DR. The role of calmodulin as a signal integrator for synaptic plasticity. Nat Rev Neurosci. 2005;6:267-76.

48. Shimada SG, LaMotte RH. Behavioral differentiation between itch and pain in mouse. Pain. 2008;139:681-7.

49. Yackle K, Schwarz LA, Kam K, Sorokin JM, Huguenard JR, Feldman JL, et al. Breathing control center neurons that promote arousal in mice. Science. 2017:355:1411-5
50. Takeuchi T, Duszkiewicz AJ, Sonneborn A, Spooner PA, Yamasaki M, Watanabe $\mathrm{M}$, et al. Locus coeruleus and dopaminergic consolidation of everyday memory. Nature. 2016;537:357-62.

51. Zhuo M. Cortical excitation and chronic pain. Trends Neurosci. 2008:31:199-207.

52. Bruinstroop E, Cano G, Vanderhorst VG, Cavalcante JC, Wirth J, Sena-Esteves $\mathrm{M}$, et al. Spinal projections of the A5, A6 (locus coeruleus), and A7 noradrenergic cell groups in rats. J Comp Neurol. 2012;520:1985-2001.

53. Stone LS, Broberger C, Vulchanova L, Wilcox GL, Hokfelt T, Riedl MS, et al. Differential distribution of alpha2A and alpha2C adrenergic receptor immunoreactivity in the rat spinal cord. J Neurosci. 1998;18:5928-37.

54. Olave MJ, Maxwell DJ. Axon terminals possessing the alpha 2c-adrenergic receptor in the rat dorsal horn are predominantly excitatory. Brain Res. 2003; 965:269-73.

55. Hirschberg S, Li Y, Randall A, Kremer EJ, Pickering AE. Functional dichotomy in spinal- vs prefrontal-projecting locus coeruleus modules splits descending noradrenergic analgesia from ascending aversion and anxiety in rats. eLife. 2017:6:1-26.

56. Liauw J, Wu L, Zhuo M. Calcium-stimulated adenylyl cyclases required for long-term potentiation in the anterior cingulate cortex. J Neurophysiol. 2005;94:878-82

57. Wang H, Xu H, Wu LJ, Kim SS, Chen T, Koga K, et al. Identification of an adenylyl cyclase inhibitor for treating neuropathic and inflammatory pain. Sci Transl Med. 2011;3:65ra63.

58. Koga K, Li X, Chen T, Steenland HW, Descalzi G, Zhuo M. In vivo whole-cell patch-clamp recording of sensory synaptic responses of cingulate pyramidal neurons to noxious mechanical stimuli in adult mice. Mol Pain. 2010;6:62.

59. Toyoda H, Zhao MG, Zhuo M. Enhanced quantal release of excitatory transmitter in anterior cingulate cortex of adult mice with chronic pain. Mol Pain. 2009;5:4

60. Zhao MG, Ko SW, Wu LJ, Toyoda H, Xu H, Quan J, et al. Enhanced presynaptic neurotransmitter release in the anterior cingulate cortex of mice with chronic pain. J Neurosci. 2006;26:8923-30.

61. Zhang TT, Shen FY, Ma LQ, Wen W, Wang B, Peng YZ, et al. Potentiation of synaptic transmission in rat anterior cingulate cortex by chronic itch. Mol Brain. 2016;9:73.

\section{Publisher's Note}

Springer Nature remains neutral with regard to jurisdictional claims in published maps and institutional affiliations.

Ready to submit your research? Choose BMC and benefit from:

- fast, convenient online submission

- thorough peer review by experienced researchers in your field

- rapid publication on acceptance

- support for research data, including large and complex data types

- gold Open Access which fosters wider collaboration and increased citations

- maximum visibility for your research: over $100 \mathrm{M}$ website views per year

At $\mathrm{BMC}$, research is always in progress.

Learn more biomedcentral.com/submissions 